\title{
Inform, Involve, and Interact- Bring the Society and Its Members Together
}

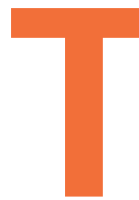

he editors of IEEE Signal Processing Magazine (SPM) are working very hard to inform, involve, and interact with SPS members. Our goal is to make SPM the primary channel of communication between the Society and its members.

Inform is the Society's goal to consistently communicate information to its members. $S P M$ is the main vehicle for providing information to SPS members. In addition to news about the Society, our magazine contains feature articles with that bring timely technical information. In the column and forum area, we write about the latest trends in signal processing technology and applications to solve real-world problems. In 2004, we started a "Life Sciences" column, edited by Jie Chen, that explores potential applications of signal processing technology in all areas of life science research. We have the highly acclaimed "DSP Tips and Tricks" column, edited by Rick Lyons and Amy Bell. We also began a new "DSP Applications" column, edited by Eli Saber, that explores novel applications of DSP technology. Twice a year, we publish Will Strauss's "DSP Market Musings" column to tell the business side of the story. For our academic members, the "Signal Processing Education" column, edited by Ken Barner, provides information on recent advances in the DSP education curricula and pedagogy. The "Lecture Notes" column, edited by Jian Li and Petre Stoica, offers a forum for instructors and researchers to share their innovations for teaching DSP. The "New Products" department, edited by Konstantinos Konstantinides, and the "Book Review," edited by John Sorensen, also provide timely information.
Involve stands for the feedback from SPS members to the Society. Many new SPS members have wondered how to get involved in SPS activities, aside from submitting or reviewing technical papers for SPS journals. This is particularly important to our industrial members, who develop DSP products rather than conduct research on DSP theory and algorithms. The SPS sponsors three major conferences and numerous workshops. The "Conference Spotlight" column in SPM highlights these events. SPS also sponsors technical workshops, in which a small number of DSP professionals exchange their ideas in a relaxed setting. Attending our conferences or workshops is a good first step to involvement in the Society. Then propose a special session or a tutorial or even to organize a meeting. Within the scope of $S P M$, readers are encouraged to get involved by proposing special issues and submitting white papers for feature articles. For the column and forum area, we welcome perspective authors to e-mail their proposed articles to associate editors, or to me personally. At the present, there are two columns that have a particularly human touch. The "Leadership Reflections" column, edited by Arye Nehorai and Timothy Thomas, allows readers to learn from the valuable experiences of leaders in our community. The "DSP History" column, edited by Adriana Dumitras and George Moschytz, highlights important historical events and developments in DSP and shares the thoughts of pioneers in the DSP field.

Interact refers to the bidirectional communication between the Society and its members. As the fourth largest IEEE society with 17,000 members, it would be quite a challenge to facilitate one-on- one, bidirectional communication with each member. IEEE provides an excellent Web site that can resolve most membership-related questions. At SPM, we strive to provide a number of mechanisms to facilitate reader interaction. Over the past two years, Forum Editors Mauro Barni, Konstantinos Konstantinides, and Thomas Kaiser have helped launch several forums where experts are invited to express their opinions on a variety of controversial subjects related to DSP. We hope readers will interact by providing their opinions on the forum articles. We also encourage readers to propose forum discussion topics and volunteer to host forum discussions. In "Share Your Thoughts," we publish readers' feedback to articles as well as their opinions on issues concerning SPS and the DSP community. This is your magazine. We editors are always eager to learn: Are you being well served by this magazine?

Over the past two years, the columns and forum area has flourished, thanks to new ideas and wonderful articles. As the area editor, I would like to thank all the contributing authors and hard-working associate editors. Your efforts have a profound impact on SPM's ability to inform, involve, and interact with all our readers.

A wise person said: "No one can do everything, but everyone can do something." At SPM, the editors are working hard, always realizing that we can not do everything without informing, involving, and interacting with you.

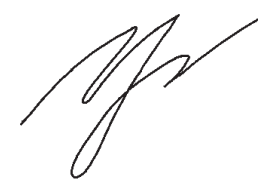

